\title{
Desafios para o Ensino de Leitura e Escrita no Brasil: \\ Heterogeneidade e Contato Linguístico
}

\author{
Challenges to the Teaching of Writing and Reading in \\ Brazil: Heterogeneity and Linguistic ContaCt
}

\author{
Marília de Nazaré FERREIRA-SILVA* \\ Thomas Massao FAIRCHILD** \\ Claudemir BELINTANE***
}

Resumo: Este trabalho discute alguns dos desafios de se ensinar a ler e escrever no Brasil hoje, face à heterogeneidade característica das salas de aula contemporâneas e à enorme variedade de situações de escolarização encontradas no território nacional. Em vista disso, cotejamse duas experiências de formação de professores que, em sua diferença, ilustram desafios peculiares da educação no Brasil - a saber: a superação dos entraves que ainda limitam o acesso à leitura e à escrita em meios urbanos e a construção de alternativas de ensino coerentes com as especificidades locais em contextos bilíngues. Na primeira experiência, um grupo de estudantes tem atuado junto a professoras-alfabetizadoras da Escola de Aplicação da UFPA com o intuito de detectar as distintas posições subjetivas assumidas pelas crianças diante da escrita e construir abordagens baseadas na escuta de suas singularidades. Na segunda experiência, realizada numa comunidade indígena do sudeste do Pará, estudantes de graduação do curso de Letras da UFPA participaram

* Doutora em Linguística pela Universidade Estadual de Campinas (2003). Professora associada da Universidade Federal do Pará. Contato: marilia@ufpa.br ** Doutor em Educação pela Universidade de São Paulo (2007). Professor adjunto da Universidade Federal do Pará. Contato: tmfairch@yahoo.com.br *** Doutor em Educação pela Universidade de São Paulo (1997). Professor da Universidade de São Paulo. Contato: claubelintane@uol.com.br 
durante dois anos de um trabalho de alfabetização em língua materna (indígena), vivenciando a perspectiva intercultural na prática docente. Com base nessas experiências, procuramos explicitar nos dados alguns problemas de caráter mais geral e esboçamos algumas possibilidades de enfrentamento.

Palavras-chave: Alfabetização; Oralidade; Línguas indígenas.

Abstract: This paper discusses some current challenges to the teaching of writing and reading in Brazil, considering that contemporary classrooms are typically heterogeneous and the schooling contexts in the country vary immensely. In that light, we compare two experiences in teacher education that, although different, exemplify peculiar challenges to education in Brazil, such as surpassing the obstacles that still limit access to literacy in urban environments and creating alternative pedagogical proposals fit to local demands, especially in bilingual contexts. In that first experience, a group of undergraduates has been working with teachers from elementary school in the School of Application of the Federal University of Pará (UFPA) with the intent to detect different subjective positions assumed by children when faced with the written language and craft teaching approaches based on that. In the latter experience, carried out in an indigenous community in southeastern Pará, undergraduates in Language Arts from UFPA took part in a program meant to teach writing and reading in first-language (indigenous) for two years. Based on these two experiences we point out, in our data, some educational problems of general concern and outline some possible ways to face them.

Key-words: Teaching writing and reading; Orality; Indigenous languages.

\section{Introdução}

Uma das maiores dificuldades da Educação contemporânea é compreender, contextualizadamente, o fenômeno da heterogeneidade na escola pública, sobretudo em países onde as diferenças socioeconômicas, linguísticas e culturais constituem a norma, como é o caso do Brasil. As defasagens entre nível de leitura e ciclo, reveladas, nestas últimas décadas, pelas avaliações do SAEB/Prova Brasil, 
mostram que, apesar de alguns indícios de melhora nas três últimas avaliações, as habilidades básicas necessárias à progressão escolar ainda constituem um problema e um desafio extremamente complexos para a educação brasileira. $\mathrm{O}$ percentual de alunos com pontuação abaixo de 150, que corresponde a alunos que ainda não dominam as habilidades mais básicas de leitura, representa, ao longo dos ciclos, uma complexidade pedagógica cuja compreensão se situa acima dos recursos e estratégias utilizadas pelos professores, escolas e sistemas de ensino.

Os percentuais mostrados no quadro 1 permitem inferir a situação de heterogeneidade nas salas de aula brasileiras que resulta dos diferentes níveis de leitura:

\section{Quadro $1^{1}$}

\begin{tabular}{|c|c|c|c|c|c|c|c|c|c|c|c|}
\hline Ano & nivel0 & Nivel1 & nivel2 & nivel3 & nivel4 & Nivel5 & nivel6 & nivel7 & nivel8 & nivel9 & ni \\
\hline 2001 & $21,88 \%$ & $18,63 \%$ & $20,12 \%$ & $18,26 \%$ & $12,05 \%$ & $5,77 \%$ & $2,23 \%$ & $0,84 \%$ & $0,22 \%$ & $0,01 \%$ & $0,00 \%$ \\
\hline 2003 & $17,94 \%$ & $18,05 \%$ & $20,94 \%$ & $20,13 \%$ & $13,19 \%$ & $6,58 \%$ & $2,32 \%$ & $0,53 \%$ & $0,25 \%$ & $0,07 \%$ & $0,00 \%$ \\
\hline 2005 & $15,02 \%$ & $18,31 \%$ & $21,84 \%$ & $20,16 \%$ & $14,10 \%$ & $6,88 \%$ & $2,67 \%$ & $0,79 \%$ & $0,24 \%$ & $0,00 \%$ & $0,00 \%$ \\
\hline
\end{tabular}

Somando-se os níveis "zero" e "um", teoricamente, haveria, nas salas de aula de $4^{a}$ série, um percentual acima de trinta por cento de alunos cujo nível de leitura corresponderia aproximadamente ao de alunos de $1^{\mathrm{a}}$ e $2^{\mathrm{a}}$ séries, ou seja, alunos que estariam às voltas com o domínio das habilidades mais básicas de leitura (com dificuldades que vão desde o domínio da relação grafema-fonema à leitura subvocalizada, lenta, sem a fluência necessária às habilidades inferenciais). Com base nessas médias, pode-se inferir que, nas escolas públicas brasileiras, em cada uma de suas salas de $4^{\mathrm{a}}$ séries, tendem a conviver alunos de, no mínimo, cinco níveis diferentes, sendo que, por volta de $70 \%$ estariam abaixo da média cinco (levando em consideração a

${ }^{1}$ Disponível em: < http://provabrasil2009.inep.gov.br/> . Acesso em: 30 abr. 2011. Até o momento da finalização deste texto não foi possível localizar no site do INEP os relatórios referentes aos resultados das avaliações de 2007 e 2009, de modo que trabalhamos com os dados mais atuais disponibilizados pelo governo na rede. 
pontuação de 2005). Seguindo os percentuais de 2005, a projeção é de que, numa sala de aula hipotética composta por 35 alunos, a composição da turma seria aproximadamente a seguinte:

\section{Quadro 2}

\begin{tabular}{|l|c|c|c|c|c|c|}
\hline Nível & $\mathbf{0}$ & $\mathbf{1}$ & $\mathbf{2}$ & $\mathbf{3}$ & $\mathbf{4}$ & $\mathbf{5}$ \\
\hline $\begin{array}{l}\text { Quantidade de } \\
\text { alunos }\end{array}$ & 5 & 6 & 7 & 7 & 4 & 5 \\
\hline
\end{tabular}

Levando em conta que o Plano de Desenvolvimento da Educação (PDE) adota os parâmetros fixados pelo movimento Compromisso de Todos Pela Educação, e, entre esses, a média para a $4^{\mathrm{a}}$ série (quinto ano do EF de nove anos) deveria se posicionar acima de 200 pontos (nível 4) e, para a $8^{a}$ série (nono ano), acima de 275 pontos (nível 7), (BRASIL, 2008, p. 11), observa-se que o desafio de formar professores para ensinar a leitura e a escrita é ainda um problema bastante concreto no Brasil.

Some-se a isso o fato de que os dados acima não recobrem algumas situações sobre as quais se permanece sabendo muito pouco, e que, no entanto, são profundamente peculiares ao ensino brasileiro. No relatório que apresenta os primeiros dados do SAEB 2005, publicado em fevereiro de 2007, por exemplo, uma nota afirma que "para a composição do estrato rural não foi incluída a Região Norte em 1997 e em 1999 e 2001, apenas participaram os estados da Região Nordeste, Minas Gerais e o Mato Grosso" (BRASIL, 2005, p. 6). De forma semelhante, o PISA - exame cujos resultados foram muito comentados no país - também não contou com dados do interior dos Estados da região Norte, como o relatório afirma:

Por razões operacionais e de custo, a população de referência brasileira excluiu os estudantes das escolas rurais da Região Norte e, também, aqueles das escolas rurais com menos de 5 alunos matriculados, que representam $0,4 \%$ da população de referência. (PISA 2000, 2001, p. 23) 
A pouca consistência dos dados dessas avaliações quando se trata das regiões interioranas do norte do país significa que as estatísticas produzidas a partir de seus resultados, objetivamente, são muito pouco ou nada representativas das situações de escolarização peculiares a esse contexto, como é o caso das escolas em comunidades ribeirinhas, quilombolas ou - caso de que trataremos mais detidamente - em áreas indígenas. Essas realidades são bastante complexas, inclusive do ponto de vista linguístico, uma vez que envolvem variedades do português ainda pouco documentadas e situações de contato entre línguas, na maior parte das vezes envolvendo o português e línguas indígenas. Embora o artigo 26 da Lei 9.394 (LDB/96) (BRASIL, 1996) preveja que os currículos do Ensino Fundamental e Médio sejam compostos por uma "base nacional comum" e uma "parte diversificada, exigida pelas características regionais e locais da sociedade, da cultura, da economia e da clientela", é notório que situações como essas ainda carecem de políticas específicas e permanecem pouco contempladas pelos sistemas de ensino e avaliação.

Estima-se que, no Brasil, ainda são faladas 180 línguas indígenas. Começam a surgir iniciativas positivas do ponto de vista do reconhecimento e preservação dessa diversidade linguística, como é o caso do Decreto $7.387,{ }^{2}$ que institui o Inventário Nacional da Diversidade Linguística (INDL). Há, também, casos isolados de municípios, como São Gabriel da Cachoeira, no Amazonas, e Tacuru, no Mato Grosso do Sul ${ }^{3}$, que adotaram como língua oficial, além do português, línguas indígenas faladas em seu território. Não obstante, sabe-se que a situação de um grande número dessas línguas não é favorável e que o contato com o português, na maioria dos casos, tende a levá-las ao desaparecimento.

Em vista disso, a educação indígena se vê diante de questões diferentes daquelas apontadas pelos dados do SAEB e do INEP, que envolvem a elaboração de medidas para preservação e revitalização

${ }^{2}$ Disponível em: <http://www.planalto.gov.br/ccivil_03/_Ato2007-2010/ 2010/Decreto/D7387.htm>.

${ }^{3}$ Disponível em: < http://www.jusbrasil.com.br/noticias/2239569/cidade-demato-grosso-do-sul-adota-o-guarani-como-lingua-oficial> Acesso em: 28 abr. 2011. 
de línguas em risco de extinção e requerem a realização de trabalhos que ainda se encontram longe de completar-se, como a descrição léxicogramatical, o estabelecimento de ortografias, a formação de professores e a elaboração de programas de ensino consistentes. É imperativo que, simultaneamente à descrição dessas línguas, trabalhos na área de ensinoaprendizagem e formação de professores também sejam realizados com base nas especificidades desses contextos, o que poderia ajudar a consolidar o caráter de "língua de valor" às línguas indígenas e dar, assim, um passo importante para impedir seu desaparecimento.

Em grandes linhas, portanto, pode-se afirmar que as avaliações que vêm sendo empreendidas pelo governo federal nas últimas décadas começam a demonstrar, para alguns contextos educacionais, um quadro fortemente caracterizado por uma heterogeneidade que se instaura a partir da relação do sujeito com a escrita dentro de uma cultura predominantemente letrada. Essas mesmas avaliações, por falta ou insuficiência de dados, sequer começam a ilustrar outros contextos, como é o caso de muitas situações encontradas na região amazônica, em que a presença de línguas e culturas em contato é a tônica nas quais a relação com a escrita não diz respeito apenas às singularidades do sujeito, mas também ao encontro de heranças culturais diferentes, que enfatizam de modos diversos a oralidade e o letramento.

Em suma, portanto, estas considerações nos mostram que os desafios da Educação no Brasil têm uma dimensão maior do que aquela que nos apontam as estatísticas de órgãos governamentais, e o ensino de línguas tem uma parte vital a cumprir no enfrentamento de muitas dessas questões.

Nos itens a seguir, buscaremos ilustrar de forma mais concreta esses desafios, relatando duas experiências em contextos distintos. A primeira delas refere-se ao quadro mais bem documentado pelas avaliações nacionais - trata-se de uma experiência com alfabetização nas séries iniciais do Fundamental de nove anos na Escola de Aplicação da UFPA. Procuraremos mostrar que as questões apreendidas a partir de uma leitura estatística, se servem como ponto de partida, requerem outro tipo de trabalho por parte do professor para construir um ensino sensível à singularidades que os sujeitos manifestam. A segunda experiência relatada refere-se ao que os dados das avaliações pouco recobrem: trata-se de um trabalho de alfabetização em língua indígena realizado numa comunidade Parkatêjê situada no sudeste do Pará. 


\section{Experiência de alfabetização na EAUFPA}

A experiência que relataremos aqui pertence às atividades do projeto $O$ desafio de ensinar a leitura e a escrita no contexto do Ensino Fundamental de nove anos e da inserção do laptop na escola pública brasileira ${ }^{4}$. $\mathrm{O}$ projeto está sendo realizado por três equipes, situadas respectivamente na Universidade de São Paulo, na Universidade Estadual do Rio Grande do Norte (em Pau dos Ferros) e na Universidade Federal do Pará (em Belém). Os dados a que nos referiremos são provenientes do trabalho da equipe de Belém.

Na Escola de Aplicação da UFPA, a equipe do projeto está acompanhando todas as turmas do $1^{\circ}$ e $2^{\circ}$ anos do Ensino Fundamental de nove anos com o objetivo de elaborar diagnósticos individuais e, com base neles, propor elementos para o ensino, tirando proveito sobretudo dos gêneros da oralidade e dos recursos tecnológicos. Cerca de 120 alunos estão sendo contemplados pelo projeto, divididos em sete turmas (três turmas de $1^{\circ}$ ano e quatro de $2^{\circ}$ ). Cada turma é acompanhada por uma professora e uma estagiária de graduação em Letras ou Pedagogia.

Uma das premissas do projeto, que nos interessa mais de perto por ora, é a de que nas salas de aula de hoje defrontamo-nos com dois tipos distintos de heterogeneidades que os resultados de avaliações como o SAEB e o PISA não conseguem distinguir. O primeiro deles é a heterogeneidade que constitui os sujeitos e marca a diferença de conhecimento e postura quando uma criança ingressa no Ensino Fundamental. Algumas crianças, por exemplo, chegam à escola conhecendo as letras do alfabeto, e outras não. Há crianças que chegam estando profundamente imersas no universo da ficção e da fantasia e outras que se mostram muito mais ligadas ao mundo dos afazeres práticos. Algumas crianças possuem grandes repertórios de textos na memória, ao passo que outras conseguem reter e reproduzir apenas fragmentos.

Um segundo tipo de heterogeneidade é aquela que é produzida pela própria escola, a partir de diferenças iniciais ou do desenlace das

\footnotetext{
${ }^{4}$ Projeto coordenado nacionalmente por Claudemir Belintane (USP) e financiado pelo edital nº 038/2010/CAPES/INEP - Observatório da Educação.
} 
questões subjetivas de cada criança. Neste caso, dada à forma como a alfabetização é tradicionalmente conduzida, a diferença mais decisiva em geral tem a ver com o quanto uma criança está familiarizada visualmente com as letras do alfabeto, já que, na maior parte do tempo, ela será instada a reconhecer letras e palavras pela forma ou a reproduzilas de seu punho. Essa diferença, às vezes absolutamente casual, somase às maneiras peculiares como as crianças reagem à escrita. Como não é raro que a letra escrita inspire algum tipo de angústia (POMMIER, 1993), há certas combinações que são explosivas. Isto pode trazer grandes prejuízos aos alunos, uma vez que essa angústia gera isolamento e contribui para a constituição de grupos marginais à condução da aula. À medida que o tempo passa, consolidam-se resistências que, possivelmente, vão constituindo os percentuais que aparecem nos finais de ciclo. Uma das preocupações do projeto é identificar precocemente essa tendência e tentar incluir os alunos a partir de um manejo pedagógico que leve em conta sua cultura oral e expansão de suas potencialidades de compreensão oral e iconográfica.

$\mathrm{Na}$ etapa em que se encontra atualmente, a equipe de Belém tem trabalhado na elaboração de um diagnóstico de cada aluno que, dentre outra coisas, ajude a destrinchar as heterogeneidades decorrentes da subjetividade dos alunos daquelas que podem estar começando a se produzir na escola. Este diagnóstico difere de outras propostas de que tenhamos conhecimento ${ }^{5}$ por partir do pressuposto de que a escrita tem uma dupla origem, na imagem e na oralidade (BELINTANE, 2008), e por incluir elementos que se referem tanto às capacidades leitura e escrita quanto à oralidade e à memória dos alunos. Desde essa perspectiva, assumimos que a familiaridade e o domínio da criança sobre certos gêneros da oralidade - em especial aqueles marcados pelo ludismo, pelo jogo com a linguagem e pela elaboração poética ${ }^{6}$ podem ser decisivos em termos de favorecer a aprendizagem da

${ }^{5}$ Sobretudo da noção de diagnóstico oriunda do construtivismo, que se baseava exclusivamente na escrita.

${ }^{6}$ Incluem-se aí gêneros como contos cumulativos, trava-línguas, acalantos, fórmulas de escolha, trovas, parlendas, adivinhas, a "língua do pê" e seus similares, além de narrativas de diversos matizes, como contos de fadas, lendas, mitos, fábulas, causos etc. 
escrita, tanto quanto ou mais do que o contato com livros ou situações tipicamente pensadas como "de letramento".

Embora os dados da pesquisa ainda sejam iniciais, já é possível ilustrar algumas consequências da perspectiva adotada. Trataremos em especial de uma questão detectada em uma turma do $2^{\circ}$ ano e do encaminhamento que foi dado a ela com base nas considerações que fizemos sobre a heterogeneidade dos grupos.

Os dados produzidos pelas pesquisadoras em sala de aula, por meio de diários de campo, a princípio sugerem que as turmas vão razoavelmente bem, exceto por alguns alunos “problemáticos”. Durante as primeiras semanas de reuniões, esses alunos ocuparam a cena falou-se bastante de episódios de indisciplina, preguiça, choro, recusa de participar das atividades e assim por diante. Com o tempo, a técnica da escrita foi se apurando e informações mais pontuais começaram a aparecer também sobre aqueles alunos que, por assim dizer, preferem ficar longe dos holofotes. Isto foi providencial para o surgimento de notas como a seguinte ${ }^{7}$ :

(1) Depois [a professora] escreveu no quadro a palavra "ambiente" e pediu que os alunos fizessem a leitura; em seguida foi apontando letra por letra e perguntando para eles. Foi neste momento que percebi que alguns alunos não estavam concentrados e o que chamou minha atenção foi a aluna P., que no momento das perguntas (sobre a palavra "ambiente"), tinha um olhar angustiante por não saber o que estava escrito no quadro e por seus amigos saberem, então ela tentava "fingir" que estava lendo. A professora repetiu letra por letra para ela, porém ela não compreendia. [15/03/2011]

Situações como essa são muitas vezes difíceis de perceber do ponto de vista do professor-alfabetizador que, atuando sozinho com um grupo de crianças, precisa desdobrar-se para atentar simultaneamente à condução das atividades e às posturas individuais dos alunos - especialmente os que optam por não chamar atenção.

7 Todos os excertos utilizados neste artigo são do diário de campo da aluna Lílian Costa dos Santos, responsável pelo acompanhamento da turma em questão. 
A suspeita de uma criança que, diante de uma tarefa que parte dos colegas aparentemente consegue "tirar de letra", finge ler, levou-nos a buscar nos diários de campo outras ocorrências relacionadas a P. Os excertos abaixo reúnem observações esparsas que, justapostas, traçam quase por si mesmas um retrato bastante claro da situação desta criança em sala de aula, mas que passam facilmente despercebidas no cotidiano da turma.

(2) Durante a atividade comigo, a P. não se concentrava, ficava de vez em quando olhando para as figuras de alguns cartazes sobre o meio ambiente, qualquer barulho chamava a sua atenção, quando realmente se concentrava conseguia reconhecer algumas vogais (“a”, "ip" e as vezes "e") (...) [22/03/2011]

(3) Escrita da P. [numa atividade de ditado]

1- POLVI/ dedão

2- AIO/ papão

3- AÑI/ pão

4- Raim/ não

5- Rian/ mamão

6- $\mathrm{ANl} /$ leão

7- Rolia/ sabão

8- ANIN/ avião

9- ANIA/ anão

10- AINA/ pião

11- JNA/ João

[24/03/2011]

(4) Ao pronunciar a primeira palavra [do ditado, que era "dia"] o M. (07 anos) disse: Meu nome! A professora então respondeu que seria impossível ele errar porque não era o nome dele e sim o sobrenome, que era Dias. A aluna P. (06 anos) disse que não sabia escrever dia. [29/03/2011]

(5) Ao terminarem de cantar a professora perguntou: - Quantas letras tem a palavra Mariana? E ela começou a falar letra por letra com eles, porém a P. (06 anos), o A. (07 anos) e o G. (07 anos) não falavam. [31/03/2011] 
O excerto (3) mostra uma situação semelhante à dos diagnósticos de linha construtivista, que nos levaria a concluir que P. tem uma escrita "pré-silábica" - conforme a nomenclatura de Ferreiro (1985). Ela dá sinais de conhecer poucas letras (utiliza dez) e talvez ter retido fragmentos visuais de partes de palavras (como "polvi"). No mais, controla a quantidade e a ordem das letras para diferenciar uma palavra da outra na lista, sem dar nenhum indício de lidar com a relação grafemafonema.

As informações levantadas a partir de um diagnóstico dessa natureza são relevantes, mas revelam uma situação mais complexa se cotejada com os demais excertos, em que se observa a aluna em situações de leitura também. Sem entrar em detalhes, o que se pode notar é que, no período que vai de 15 a 31 de março - as duas primeiras semanas de observação da turma - a aluna P. (juntamente com alguns outros, como A. e G.) permaneceu alheia a todas as atividades que envolviam diretamente o ensino de leitura e escrita. Durante essas atividades, a aluna distraía-se, fingia participar ou valia-se de trechos memorizados para responder às tarefas propostas. Pode-se imaginar o resultado dessa rotina ao longo de um tempo maior: a tendência é que alunos como P. construam grandes resistências à escolarização e que, com o passar dos anos, acabem se isolando de uma forma ou de outra, inclusive pela adesão de certos estereótipos que vão se tornando cada vez mais difíceis de serem quebrados, como o de "alunos com problemas na alfabetização", "alunos desinteressados”, etc.. Aí reside, portanto, a importância de pesquisas que busquem detectar precocemente essa tendência.

${ }^{8}$ Não se pode deixar de notar que a dificuldade de quebrar esses estereótipos reside também no fato de que, às vezes, eles são "verdadeiros" - isto é, que muitas vezes de fato o aluno tachado como "desinteressado" é mesmo um aluno desinteressado, e assim por diante. A questão que colocamos, no entanto, é que a gênese não só do estereótipo, mas também dos traços subjetivos em que esses estereótipos ocasionalmente se baseiam - com certa razão -, podem resultar de processos situados na própria escolarização. Nesse sentido, a repetição do estereótipo acaba funcionando como mecanismo que encobre, para os sujeitos, a origem do problema com que se defrontam e a parte que assumem na manutenção desse problema. 
O que nos interessa frisar a partir dos dados expostos acima é que o alheamento de alunos como P., A. e G. decorre basicamente de dois fatores: 1) o fato de que eles conhecem muito pouco o alfabeto; e 2) o fato de que a escrita, quando ensinada em sala de aula, é sempre abordada a partir da imagem visual das letras e da tentativa de racionalização do seu funcionamento (decomposição da palavra em sílabas e letras, ensino das famílias silábicas, etc.). Essa forma de ensino parece dar resultado para uma parte das crianças, mas, para outras, resulta na impossibilidade de acompanhar boa parte das atividades escolares e, em termos subjetivos, de identificar-se firmemente à função de "aluno".

O quadro 3 sintetiza as atividades realizadas na turma de P. durante o período abrangido pelas anotações citadas. Em destaque estão indicadas as atividades que envolvem o ensino de leitura e escrita a partir do conhecimento do alfabeto.

\section{Quadro 3}

\begin{tabular}{|l|l|}
\hline Data & Tarefas \\
\hline $15 / 03$ & $\begin{array}{l}\text { Escutar uma história lida em voz alta pela professora } \\
\text { Desenhar uma cena da história e dar um título }\end{array}$ \\
\hline $17 / 03$ & $\begin{array}{l}\text { Contar como foram as aulas do dia anterior (conversa) } \\
\text { Ler uma palavra (AMBIENTE) escrita na lousa } \\
\text { Ler a palavra letra por letra } \\
\text { Responder a perguntas sobre o que é meio-ambiente (conversa) } \\
\text { Desenhar um ambiente onde gostariam de estar } \\
\text { Recortar figuras e colar para formar um ambiente }\end{array}$ \\
& $\begin{array}{l}\text { Lembrar-se de um trava-línguas e dizer } \\
\text { Ler um trava-línguas, copiado da lousa no caderno de } \\
\text { caligrafia, em silêncio } \\
\text { Ler coletivamente o trava-línguas em voz alta (três vezes) } \\
\text { Escrever um novo trava-línguas no caderno } \\
\text { Pintar de verde a palavra sapo, pintar de amarelo a palavra } \\
\text { com mais letras, pintar de azul a palavra com } 7 \text { letras } \\
\text { Escutar uma explicação sobre verso, rima e estrofe } \\
\text { Circular o verso de que mais gostou } \\
\text { Escolher um livro para ler para a professora }\end{array}$
\end{tabular}

9 "Olha o sapo dentro do saco / O saco com o sapo dentro / O sapo batendo papo / E o sapo soltando vento”. 


\begin{tabular}{|l|l||}
\hline $24 / 03$ & $\begin{array}{l}\text { Lero livro em voz alta para a professora } \\
\text { (Alunos que não conseguem ler): brincar com quebra-cabeças para } \\
\text { reconhecer letras etc. }\end{array}$ \\
& $\begin{array}{l}\text { Contar como foram as aulas do dia anterior } \\
\text { Correção da lição de casa: dizer a resposta de uma adivinha } \\
\text { Escutar uma explicação sobre a nasalização -ão } \\
\text { Escrever palavras com -ão (ditado) } \\
\text { Desenhar os objetos correspondentes às palavras ditadas } \\
\text { Recortar de revistas palavras com - ão }\end{array}$ \\
\hline $\begin{array}{l}\text { Encontrar outras palavras dentro da palavra MARIANA } \\
\text { Dizer quantas letras tem a palavra MARIANA } \\
\text { Dizer quantas vogais e consoantes tem a palavra MARIANA } \\
\text { Dizer quantas sílabas tem a palavra MARIANA } \\
\text { Encontrar outras palavras dentro de uma lista de palavras- } \\
\text { valise (SOLDADO, SAPATO, BOLA), mostradas por escrito } \\
\text { (Aula de matemática) }\end{array}$ \\
\hline
\end{tabular}

Algumas considerações podem ser feitas a partir do quadro 3. Primeiramente, há que se notar que as atividades destacadas representam momentos da aula em que alunos como P., A. e G., por não conhecerem o alfabeto, não têm o que fazer, pois as tarefas exigem operar justamente aquilo que eles ainda não conhecem. Ao longo de duas semanas, podese perceber que se trata de uma grande quantidade de tempo durante o qual, para parte dos alunos, resta apenas observar os colegas e imitálos.

As atividades restantes, de cunho variado, são momentos que permitiriam a participação desses alunos - e os relatórios demonstram que eles assim o fazem. No entanto, tratam-se de atividades que não os auxiliam a resolver os problemas que os impedem de participar das demais, são atividades que envolvem ações comuns do falante, como escutar as explicações da professora ou falar sobre determinado assunto. Nesse sentido, embora sejam atividades faladas, essas tarefas não envolvem a oralidade no sentido em que se a concebe dentro do projeto, isto é, como estando relacionada a textos lúdicos que demonstram um tratamento poético da linguagem e exigem um trabalho da memória.

\footnotetext{
10 "Numa casa tem quatro cantos, em cada canto tem um gato, cada gato vê três gatos. Quantos gatos tem na casa?"
} 
Os gêneros da oralidade, com efeito, prefiguram movimentos latentes à escrita, uma vez que jogam com as semelhanças sonoras (nas rimas), com as possibilidades de segmentação (na métrica) e permuta de elementos significantes (nos trava-línguas, por exemplo), demonstram formas relativamente fixas e com acabamento semelhante ao dos textos de gêneros escritos (e diferentemente dos textos conversacionais), permitem o estabelecimento de redes intertextuais (pela recorrência de temas ou de "frames", por exemplo, como o do "engodo" em contos de fadas e fábulas ${ }^{11}$ ), etc.. Ao contrário de textos como estes, atividades como conversar ou ouvir fixam-se num uso ordinário e pragmático da linguagem que pouco se aproxima das questões envolvidas na escrita.

Vale destacar, também, que mesmo em outras atividades em que gêneros da oralidade aparecem, como os trava-línguas, as adivinhas e as narrativas, elas são apresentadas em sala de aula a partir da escrita e não chegam a ser trabalhados como textos orais. Note-se, por exemplo, que na aula de 22/03, as atividades realizadas a partir do trava-línguas são essencialmente atividades de cópia (o trava-línguas está copiado no caderno de caligrafia) e de leitura em voz alta, das quais alunos que ainda não conhecem o alfabeto podem participar apenas a duras custas e sem muito ganho. A memorização dos textos, que chega a ser instada pela professora, infelizmente é mais uma casualidade do que um objetivo de ensino. O mesmo ocorre com a adivinha trabalhada em 24/03, que cumpre uma função que poderia ser exercida por qualquer outro texto, de origem oral ou não. Uma consequência notável dessa forma de tratamento dos textos orais, além da perda de sua especificidade enquanto texto oral, capaz de mediar a entrada do sujeito na escrita, é a própria redução do repertório de textos vistos na escola. A proposta de copiar e ler adivinhas, travalínguas, parlendas e poemas ocupa um tempo tal que, na maior parte das vezes, só se chega a conhecer um único texto de cada gênero. Deixa-se de desenvolver, dessa forma, outro aspecto fundamental para

11 Tome-se, por exemplo, os engodos presentes nas fábulas "O galo e a raposa" e "O asno em pele de leão". O tema também é recorrente em contos populares sobre personagens que enganam a morte, o Diabo ou mesmo outras pessoas (como nas histórias de Pedro Malasartes). 
a aprendizagem da escrita que é a ampliação do repertório de textos dos alunos - textos inicialmente memorizados que podem funcionar como matriz para a leitura da letra de diversas formas (por exemplo, fornecendo estofo para a elaboração de hipóteses sobre a leitura de palavras, nomes de personagens, frases ou passagens de narrativas, e assim por diante).

Finalmente, outra parte das atividades realizadas em sala destinase ao trabalho com a imagem - ilustrado, por exemplo, pelo episódio do dia $17 / 03$, em que as crianças passaram bastante tempo desenhando e fazendo colagens para representar "um ambiente". Muitas vezes realizadas com o propósito de aguçar o olhar ou a coordenação das crianças, atividades com imagens como essas deixam escapar o que a imagem tem de relação com a escrita, que é a possibilidade de funcionar como rébus. Presente na própria história da escrita ${ }^{12}$, o rébus é, de certa forma, o mecanismo de gênese da letra, e o que o caracteriza, mais do que a presença da imagem, ainda reconhecível como representação de um objeto, é o fato de ele exigir uma leitura que abra mão da representação pictórica para destacar dela um elemento sonoro (uma "imagem acústica", como diria Saussure). Pode-se dizer, portanto, que é uma condição para aprender a ler e a escrever ser capaz de ler e montar rébus com figuras. Infelizmente, quando a imagem aparece em materiais didáticos infantis, ela quase sempre é tratada enquanto signo que representa por semelhança (portanto, pertencente a uma ordem que não da letra), a tal ponto que se arrisca dizer que sua recorrência pode inibir a entrada da criança na escrita mais do que ajudá-la por um suposto aguçamento da percepção visual ou da coordenação fina.

As atividades baseadas na operação de rébus são uma das principais estratégias propostas pelo projeto para apresentar a escrita de outra forma que não pela racionalização direta da letra - trajeto ao qual muitas crianças (e adultos, igualmente) rapidamente levantam uma série de resistências. Belintane ${ }^{13}$, trabalhando com um aluno de uma favela da Zona Oeste de São Paulo, encontrou no rébus uma solução

${ }^{12}$ Cf. as considerações de J. Allouch (1995) e Pommier (1993) a esse respeito.

${ }^{13}$ Palestra "Oralidade, leitura e alfabetização: prioridades em novos contextos", proferida em 18 de dezembro de 2010, na UFPA. 
para retomar o processo de representação escrita com o aluno, tendo em vista que este já estava desgastado por inúmeras tentativas através de outra vias.

Escrevendo seu nome com rébus acrofônicos (aproveitando só a primeira sílaba das palavras representadas pelos desenhos), escreveu o nome do aluno e insistiu para que este o lesse:

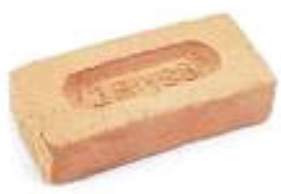

TI jolo

Figura 1

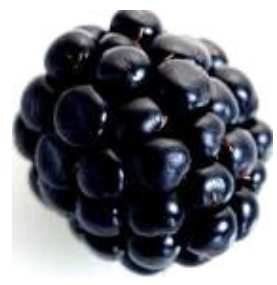

A mora

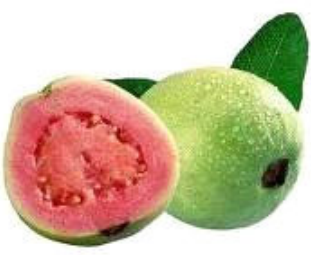

GO iaba

A técnica do rébus propõe uma leitura semelhante à que se pratica com as letras do alfabeto, ou seja, trata-se de uma lida com a perda de valor pregnante (no caso aqui, a imagem e seu sentido; no alfabeto, a imagem da letra e sua sonorização isolada) para que se recupere no lugar um significante (a imagem passa a ser uma letra silábica, corte e desprezo das sobras: aproveita-se o "TI" e se faz desaparecer o "JOLO”). Sem a presença de letras alfabéticas o aluno leu seu nome apenas com imagem-letra (rébus). A seguir, o professor desenhou as letras (retirando parte de sua pregnância imagética), tornando-a mais esquemática - portanto, mais próxima da letra - tal qual aconteceu na passagem das escritas pictográficas para as escritas silábicas no Egito, na Mesopotâmia e na China. Do desenho, chegou a uma expressão mais abstrata: "TIAGO" passou a ser escrito apenas com traços esquemáticos dos desenhos (traços metonímicos): 
Figura 2

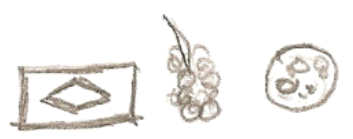

TI A GO

\section{Figura 3}
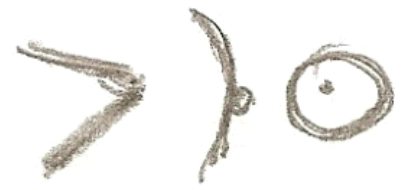

TI A GO

Após alguns jogos com rébus, o aluno conseguiu escrever algumas palavras de seu repertório (que, aliás, era quase sempre voltado para o erotismo, para o corpo - Tiago tentava sempre chocar o professor com palavrões e expressões chulas, manifestando profundo desprezo pela escolarização e pela escrita). Abaixo, usando a imagem do "Tijolo", de um "PINto" e da palavra "BUnda", escreveu "TI PIM BU" ("te pimbo", que significaria "te pego", no sentido sexual) e a seguir escreve duas expressões nonsense, mas que, pela entonação, mantém a sugestão de erotismo: "TI PIN CA" (reutilizando "Tijolo", "PINto" e acrescentando por conta própria "Caderno") e "TI PIN JÁ" (acrescentando "JAnela").

Figura 4 - Escrita em rébus de Tiago, com transliteração feita pelo professor
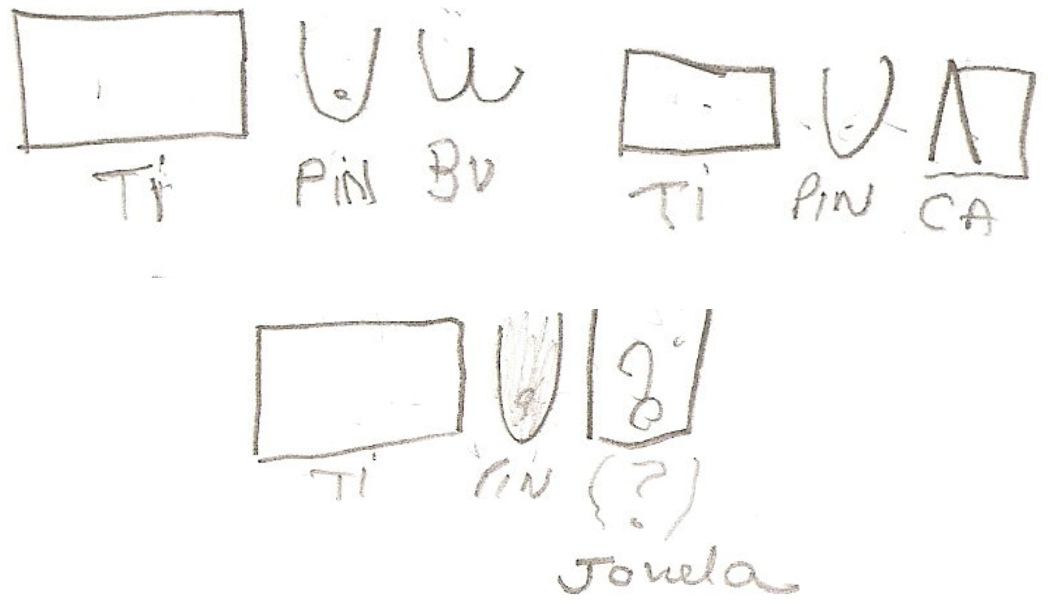
O que se vê aí é um processo de transição, que parte da pregnância da imagem (fotos de revistas pornográficas, com as quais o aluno tinha contato) para o desenho estilizado e, finalmente, para extração de letras por processo metonímico - a parte valendo pelo todo -, mas perdendo o elemento da semelhança, exatamente como aconteceu na história de nosso alfabeto:

Quadro 4 - Baseado no encarte da obra de Cagliari (2008) ${ }^{14}$

\begin{tabular}{|c|c|c|c|c|}
\hline $\begin{array}{c}\text { Hieróglifos } \\
\text { egípcios }\end{array}$ & $\begin{array}{c}\text { Significado } \\
\text { dos } \\
\text { hieróglifos } \\
\text { e do nome } \\
\text { das letras } \\
\text { semíticas }\end{array}$ & $\begin{array}{c}\text { Letras } \\
\text { semíticas } \\
\text { (fenício) }\end{array}$ & $\begin{array}{c}\text { Nome } \\
\text { das letras } \\
\text { semíticas } \\
\text { (hebraico) }\end{array}$ & Grego antigo \\
\hline 3.000 a.C. & Boi & 1.500 a.C. & & 850 a.C \\
\hline Casa & & Alef & Beth & \\
\hline
\end{tabular}

Essa retomada dos potenciais de escrita da imagem e da tradição oral infantil (os efeitos linguageiros das narrativas e dos ludismos linguísticos), além de permitirem ao aluno marginalizado um acesso mais direto à dinâmica da aula, pois todo esse conteúdo de aula é essencialmente lúdico, não deixa de ser um percurso importante, que na teoria pode ser sustentado em dois eixos de pesquisa: a história da escrita, incluindo aqui o que Havelock (1995) chamou "equação oralidade-escrita”, ou seja, as tensões e movimentos de exclusão entre a oralidade e a escrita; a psicanálise de Freud e Lacan, que assume o

${ }^{14}$ Cagliari é um dos poucos pesquisadores brasileiros que divulgou a importância da História da Escrita para a alfabetização e ensino da leitura. No entanto, atualmente, com a preponderância das teorias dos gêneros e do enfoque na circulação do texto útil (receitas, bula de remédio, logomarcas etc.), pouco se vê de sua influência no cotidiano escolar. 
rébus como uma forma de o psiquismo fazer escrita a partir de imagem. Segundo Freud (1987), essa aproximação entre imagens de sonho funcionando como rébus e o fato de que "todo o campo do chiste verbal é posto através do trabalho do sonho” (FREUD, 1987, p. 372) nos dá um caminho profícuo para entender a escrita como uma manifestação inerente à própria constituição psíquica. Como diz Lacan (1961-1962, p. 93), a escrita “esperava para ser fonetizada, e é na medida em que ela é vocalizada, fonetizada como outros objetos, que a escrita aprende, se posso dizer assim, a funcionar como escrita".

Em relação à situação específica da turma que comentamos mais acima, na qual o projeto começa a dar seus primeiros passos, as discussões realizadas pela equipe chegaram a dois apontamentos relativamente simples. Primeiro: se há uma parte dos alunos que, no $2^{\circ}$ ano, ainda não domina suficientemente o alfabeto para acompanhar as atividades da professora, e tendo em vista que essa é a maneira como a professora trabalha, é absolutamente urgente que essas crianças o dominem o mais rápido possível. Segundo: seria vantajoso que a professora alternasse esta forma de ensino da escrita, caracterizada aqui pelo fato de apresentar a letra a partir de um movimento racionalização, a outras abordagens que permitam às demais crianças aproximarem-se do funcionamento latente da escrita por vias mais sutis e indiretas. Para isso, tem-se trabalhado na confecção de materiais como baralhos de rébus e na elaboração de rotinas semanais que garantam um tempo regular de trabalho com a memória e os gêneros orais chamados "desúteis" (BELINTANE, 2006a). Espera-se que, com o desenvolvimento do projeto, que se encerra em 2014, as noções com as quais se tem feito, por enquanto, ensaios, permitam a elaboração de uma proposta mais estruturada. Mas as reflexões nos deixam com um pano de fundo para considerar a segunda experiência a ser tratada neste trabalho, realizada em um contexto bastante diferente.

\section{Experiência de alfabetização em Parkatêjê}

A heterogeneidade imanente às salas de aula brasileiras, expressa em resultados de avaliações nacionais, mas ainda pouco explorada em termos dos processos que as podem estar produzindo sistematicamente, tem um desdobramento ainda pouco percebido na própria diversidade 
dos contextos de escolarização presentes no país. Com efeito, boa parte do que se tem produzido, tanto em termos de políticas quanto em termos de pesquisa, ainda têm como pressuposto o trabalho em escolas de contexto urbano ou, ao menos, a possibilidade de sempre se poder equacionar a noção de língua materna à língua portuguesa. À margem dessa produção, no entanto, há uma série de situações em que a escola se faz cada vez mais presente e que não compartilham de muitas das características que têm sido tomadas como ponto de partida para as reflexões sobre o que significa ensinar uma língua no Brasil.

A experiência que passamos a relatar neste item remete a um desses contextos, que certamente não é o único, e que, dentre outros, talvez se possa dizer que ainda goza de relativa notoriedade graças ao interesse que as línguas indígenas despertaram, ao longo do século XX, em "grandes ciências" como a Antropologia e a Linguística. Ao lado do ensino de língua em comunidades indígenas, portanto, restam outras situações que demandam maior conhecimento e reconhecimento, mas essa discussão ultrapassa os limites do escopo deste trabalho.

Os dados que passaremos a discutir provêm do projeto de extensão "Vivências linguísticas: alfabetização de indígenas adultos em língua parkatejê, realizado junto a uma comunidade indígena localizada no sudeste do Estado do Pará, cuja língua pode ser tida como estando em perigo de extinção, durante os anos de 2010 e 2011. Este projeto tomou por base orientações presentes em diversos documentos, que expressam alguma abertura para a discussão do ensino de língua em comunidades indígenas, embora poucos deles o façam explicitamente.

Um desses documentos é o Projeto Pedagógico do Curso de Letras - habilitação em Língua Portuguesa da Faculdade de Letras da Universidade Federal do Pará ${ }^{15}$. Este projeto, ainda vigente, articula-se em três eixos: 1) uso da linguagem; 2) reflexão sobre a linguagem; 3) prática profissional. Esses eixos objetivam fornecer oportunidades para que o aluno de Letras: (i) se aproprie de conhecimentos significativos para sua atuação profissional; (ii) reflita sobre a importância e a pertinência desses conhecimentos para a compreensão, o planejamento, a execução e a avaliação de situações de ensino e aprendizagem; e (iii)

${ }^{15} \mathrm{O}$ projeto foi elaborado em 2004 e aprovado pela Resolução CONSEPE N ${ }^{\circ}$ $3.541 / 2007$. 
construa uma prática de ensino-aprendizagem com ênfase nos procedimentos de observação e reflexão para compreender e atuar em situações contextualizadas do cotidiano profissional.

Esses objetivos articulam-se com as Diretrizes Curriculares para os Cursos de Letras, segundo as quais

O objetivo do Curso de Letras é formar profissionais interculturalmente competentes, capazes de lidar, de forma crítica, com as linguagens, especialmente a verbal, nos contextos oral e escrito. Independentemente da modalidade escolhida, o profissional de Letras deve ter domínio do uso da língua ou das línguas que sejam objeto de seus estudos, em termos de sua estrutura, funcionamento e manifestações culturais, além de ter consciência das variedades lingüisticas e culturais. Deve ser capaz de refletir teoricamente sobre a linguagem, de fazer uso de novas tecnologias e de compreender sua formação profissional como processo contínuo, autônomo e permanente. (CONSELHO NACIONAL DE EDUCAÇÃO,${ }^{16} 2001$, p. 30 - grifos nossos)

Como se vê, as DCN para os Cursos de Letras fazem menção à perspectiva da interculturalidade, à relação entre oralidade e escrita, à relação entre língua e cultura e à variação linguística. Embora a leitura mais comum desses termos seja aquela que remete à formação de professores de línguas estrangeiras modernas, eles provocam uma reflexão sobre o que implicariam se tomados como referência à formação de profissionais de Letras para atuar em contextos como o da educação indígena. As experiências do projeto em questão buscam esboçar algumas respostas possíveis a essa questão.

Outros documentos que permitem uma leitura semelhante são a Constituição Federal de 1988 (OLIVEIRA, 1990) e o Referencial Curricular Nacional para a Escola Indígena (RCNEI) (BRASIL, 2005). A título de exemplo, o artigo 205 da Constituição diz que "a educação, direito de todos e dever do Estado e da família, será promovida e incentivada com a colaboração da sociedade, visando ao pleno

${ }^{16}$ Doravante, o Conselho Nacional de Educação será referido apenas como CNE. 
desenvolvimento da pessoa, seu preparo para o exercício da cidadania e sua qualificação para o trabalho" (OLIVEIRA, 1990). Esta passagem, além de instituir a obrigatoriedade da educação como direito e dever, também preconiza a participação da sociedade na construção das formas de ensino oferecidas. Se tomado no contexto do ensino de línguas indígenas, este preceito nos levaria a pensar, por exemplo, de que forma termos como "cidadania" e "trabalho" poderiam ser ressignificados a partir das experiências culturais de povos cuja matriz ontológica não é aquela de origem ocidental-europeia, bem como as consequências que isso acarretaria na elaboração de uma escola indígena.

Para além de qualquer princípio fundamentador da educação, o projeto lidou, também, com alguns aparatos teóricos que tratam da prática de ensino-aprendizagem e da linguística aplicada, para o que foram realizadas leituras dos trabalhos de Freire (1967; 1970; 1985), Lemle (1991) e Braggio (1995). Sobre a descrição da língua indígena, trabalhamos com os materiais de Araújo (1977; 1989), Ferreira (2003; 2005; 2010) e Ferreira-Silva (2010). O projeto também se baseou em algumas discussões realizadas na VI Conferência Internacional de Educação de Adultos (CONFITEA VI), realizada em Belém do Pará, em novembro de 2009, acerca de questões relacionadas à alfabetização de povos indígenas em língua materna.

$\mathrm{Na}$ comunidade em que o projeto foi desenvolvido, os falantes nativos da língua indígena, que constituem cerca de $9 \%$ da população, são apenas os mais idosos. Os outros falantes classificam-se em bilíngues passivos - com diversas faixas de bilinguismo em relação à língua indígena - e monolíngues. A língua Parkatêjê, falada por parte dos integrantes dessa comunidade, encontra-se, portanto, em acelerado processo de perda, e isto, sobretudo, devido ao contato intenso com o português. A geração jovem desconhece parcial ou totalmente a língua de seu povo. Tendo em vista essa situação, o objetivo maior do projeto foi propiciar aos mais velhos - falantes fluentes de parkatêjê o uso da língua na modalidade escrita, para que, então, agissem como difusores de sua língua e costumes aos jovens, uma vontade que foi continuamente expressa pelos próprios alunos durante o trabalho de alfabetização.

Uma das premissas do projeto, mencionada nas DCN para os Cursos de Letras (CNE, 2001), é que há um estreito relacionamento 
entre a língua de um povo e a construção de sua identidade. Por meio da língua, as sociedades humanas elaboram grande parte do conhecimento que detêm acerca do mundo. Por esta razão, quando se fala em perda linguística, inevitavelmente, fala-se também em perda de uma parte substancial da identidade étnica, uma vez que a língua é o principal instrumento por meio do qual se veiculam pensamentos, crenças, visões de mundo e conhecimentos tradicionais de um povo, entre outros aspectos.

A alfabetização em língua materna pode, portanto, ser um recurso importante para preservação, manutenção e revitalização da língua e da cultura local, por ser um estímulo ao seu uso. Além disso, o ensino dessa língua também pode atuar, de maneira concreta, como uma forma de inclusão social de um grupo minoritário à sociedade envolvente. Vale ressaltar que, em relação a isso, o chefe tradicional dos Parkatêjê, o cacique Toprãmre Jõpaipaire Krôhôkrenhum, sempre viu a escola como uma aliada no processo de preservação de suas tradições e de sua língua e, por esta razão, sempre foi um homem visionário diante da perspectiva de fomentar e favorecer ações para uma cultura de "letramento" em sua comunidade, ajustando-se às necessidades de seu povo. Este dado é crucial, uma vez que a inserção de pesquisadores em comunidades indígenas constitui um desafio peculiar a esses contextos e toda iniciativa educativa voltada a esse público defronta-se com questões que não têm par nas situações de ensino encontradas em escolas urbanas - mesmo naquelas consideradas periféricas. O projeto "Vivências linguísticas: alfabetização de indígenas adultos em língua parkatêjè", nesse sentido, foi concebido em vista de expectativas da comunidade-alvo e pôde contar com um apoio sem o qual sua realização teria sido impossível.

De outra parte, o envolvimento de estudantes da graduação do curso de Letras no projeto proporcionou uma oportunidade única de pesquisa relacionada aos estudos descritivos da língua indígena, bem como à experimentação de metodologias de ensino e aprendizagem de línguas e de propostas para a alfabetização de adultos em língua materna, a qual, nesse caso, não é a língua dos facilitadores do processo, nossos alunos de graduação.

No decorrer do trabalho, buscamos despertar nos indígenas a consciência da importância do uso escrito da língua como fator 
fundamental na sua preservação e de sua cultura. Esse objetivo, perceptível nos relatos dos próprios alfabetizandos que se dispuseram a participar das oficinas, foi o que estimulou este trabalho, desde a sua idealização até a sua execução. Deste modo, também nos foi possível vivenciar experiências interculturais na formação de professores de língua que nos parecem pertinentes para uma discussão sobre os desafios específicos do ensino de línguas em um contexto que, como vimos, ainda é pouco contemplado pelas avaliações e estatísticas do governo.

O projeto foi planejado para ser desenvolvido na forma de oficinas de alfabetização, realizadas nos períodos de férias dos estudantes de graduação, quando é possível deslocar-se para a aldeia e permanecer ali por um período mínimo de dez dias de trabalho com o grupo de adultos interessados em aprender a ler e a escrever em sua língua. É necessário esclarecer que os estudantes de graduação envolvidos no projeto realizaram o trabalho de leitura de materiais descritivos de fonética e fonologia, bem como sobre a ortografia da língua indígena, realizando eles próprios atividades de aprendizagem e de domínio dos usos ortográficos dessa língua.

A metodologia utilizada nas atividades do trabalho de alfabetização de adultos foi constituída em torno de algumas etapas pedagógicas. A primeira delas foi realizada em bases freirianas, com o "levantamento do universo vocabular", a "descoberta do universo vocabular", a "pesquisa do universo vocabular" e a "investigação do universo temático", em que os estudantes da graduação - facilitadores do processo de alfabetização - fizeram o trabalho de escolher as palavras geradoras a partir das quais os alfabetizandos tiveram o primeiro contato com o universo escrito.

Embora saibamos que Freire defendeu a alfabetização como ato de reflexão, criação, conscientização e libertação e que rejeitou a concepção de uma alfabetização como aquisição mecânica de codificação/decodificação de palavras e signos, observamos, do mesmo modo que ele, o material, o objetivo, as relações sociais e o método, materializando nossa própria concepção de alfabetização fundada em conceitos e categorias freirianos, tais como: suporte e mundo, esperança, seriedade e alegria, dialogicidade, conscientização, liberdade e transformação. Tudo isso em uma perspectiva da interculturalidade, que no dizer de Freire faz da sala de aula - que em nosso caso era a Aikrepoti, "a casa grande" -, um espaço de vida e de ação, 
[...] um local de um sadio pluralismo de idéias, uma escola moderna; uma escola alegre, competente, científica, séria, democrática, crítica e comprometida com a mudança; uma escola mobilizadora, centro irradiador de cultura popular, à disposição da comunidade, não para consumi-la, mas para recriála. O saber adquirido na escola não é um fim em si mesmo, é um instrumento de luta pela transformação social. (FREIRE, 1986, p. 15)

Nesse caso, especificamente, objetivamos que a alfabetização seja, sobretudo, uma forma de manutenção linguística e preservação de tradições culturais do povo Parkatêjê. A alfabetização realizada na perspectiva intercultural, dessa forma, transmuta conteúdos existenciais em conhecimentos socialmente validados, tomando a palavramundo como referência para a aprendizagem da palavra escrita. A palavramundo representa a articulação entre os conhecimentos e saberes cotidianos do alfabetizando e a aprendizagem da leitura e da escrita.

Com a composição do universo das palavras geradoras, cada uma relacionada a uma letra e a um som, conforme a ortografia da língua, os facilitadores passaram a exercitá-las com a participação ou coparticipação dos elementos da comunidade. Essas palavras escolhidas foram: rop (onça); pyt (sol); ãhãre (galinha); kukôj (macaco); kra (paca); kukênêre (cotia); mpojara (aves em geral); tôn (tatu); kahã (cobra); kaprãn (jabuti); inxê (mãe); inxum (pai); kaxêre (lua); hàk (gavião); pàn (arara). As palavras geradoras selecionadas obedeceram aos seguintes critérios: a riqueza fonêmica da palavra geradora; as dificuldades fonéticas da língua; e o sentido pragmático dos exercícios, ou seja, objetivamente procurou-se utilizar itens lexicais que estavam presentes no contexto cotidiano dos alfabetizandos.

Foram utilizados cartazes com as palavras escritas e os facilitadores passaram, então, a pronunciar as sílabas em voz alta, o que foi repetido, várias vezes, pelos alfabetizandos, com a finalidade de associar a forma oral à forma escrita. A seguir, a palavra geradora selecionada pelos bolsistas juntamente com os alfabetizandos foi dividida em sílabas e cada sílaba foi expandida em suas ocorrências. Por exemplo: pyti - PY - TI, que significa rio. Nesse momento, foram mostradas as famílias silábicas, buscando-se outras palavras com cada sílaba formada por uma determinada consoante e as vogais da língua. 
Foram criadas fichas de cultura, as quais eram acompanhadas dos respectivos desenhos feitos pelos próprios índios, como um estímulo a mais para a fixação do trabalho associativo das letras aos sons por elas representados, no caso de palavras de conteúdo lexical, as selecionadas para o trabalho nesse primeiro momento.

Com esse trabalho formou-se um "círculo de cultura" entre facilitadores e alfabetizandos, o que possibilitou a seleção de temas geradores para discussão através do diálogo. Dessa forma, o projeto levou os indígenas a uma maior conscientização dos problemas que os cercam, à compreensão do mundo e ao conhecimento da realidade social, no caso de si diante de uma sociedade não índia e da sociedade indígena. Indicamos a eles, então, que a alfabetização é o início de um programa de educação que desejamos manter, conforme eles também o desejem.

A avaliação do trabalho foi realizada diariamente por meio da interação entre os alfabetizandos e os facilitadores, por meio da leitura realizada pelos alfabetizandos, bem como por meio de ditados feitos em conjunto com os alfabetizandos. Eles próprios pronunciavam as palavras, que dizíamos em português e, após isso, escrevíamos todos.

Muito embora o projeto inicial tenha sido elaborado visando a atingir a meta de dez adultos alfabetizados, na primeira oficina foi possível realizar um trabalho de sondagem com apenas três deles. Essa experiência foi muito positiva porque o projeto inicial foi concebido sem que se soubesse da realidade dos alfabetizandos quanto ao conhecimento que tinham de sua língua em sua modalidade escrita nem do conhecimento que tinham de língua portuguesa também nessa modalidade.

Desse modo, o atendimento aos três indivíduos proporcionou uma espécie de diagnóstico por meio da qual se pôde compreender que há grande diversidade quanto aos conhecimentos do público-alvo. Verificamos que dois alfabetizandos conhecem bem as letras do alfabeto de língua portuguesa, o que é muito interessante para o trabalho de alfabetização em língua indígena. A dificuldade está exatamente em distinguir funções próprias das letras na escrita da língua indígena, nas seguintes situações: (a) em encontros consonantais inexistentes em português, do tipo "mra", "mpo"; e (b) em certa dificuldade de diferenciar letras do alfabeto, recaindo geralmente em equívocos quanto 
ao uso das letras 'h' e 'r' - já que na língua parkatêjê o fonema /h/ soa como o ' $r$ ' do português, mas é representado graficamente como ' $h$ ' na ortografia da língua, exceto na palavra ãhãre (galinha), em que a letra h equivale à consoante oclusiva glotal. Dificuldades dessa ordem, como se vê, não têm paralelo nos problemas enfrentados por crianças que se alfabetizam em português, e parecem derivar do fato de que a alfabetização em uma língua indígena, cuja escrita se fundamenta no alfabeto romano, produz para o sujeito, de fato, dois sistemas de escrita funcionando parcialmente com as mesmas letras (e nem sempre com as mesmas funções).

Avaliamos, também, que o pequeno número de participantes na primeira oficina deveu-se ao fato de a equipe de facilitadores, juntamente com a orientadora do trabalho, ter se hospedado em uma aldeia onde o grupo de adultos é pequeno, já que ali vivem cerca de dez famílias apenas.

A segunda oficina, realizada na Terra Indígena Mãe Maria, em fevereiro de 2011, foi bem mais concorrida, contando com vários jovens senhores e senhoras, não falantes da língua indígena, mas bem alfabetizados em português, alguns dos quais já universitários, que aderiram ao convite e participaram conosco. Os resultados do trabalho estão sendo avaliados e comparados aos da primeira etapa do processo, devendo ser apresentados em outra ocasião. Em todo caso, os dados de que dispomos já nos parecem suficientes para pontuar uma questão que perpassa todo o trabalho: uma iniciativa de ensino de língua indígena voltada à preservação da língua e da cultura requer a continuidade de reflexões sobre a articulação entre a produção de descrições linguísticas e a elaboração de programas de ensino com o objetivo específico de formar usuários da língua. Essa articulação se faria problema central na formação de professores para atuar em contextos como o de comunidades indígenas em que a língua de ensino não dispõe de uma descrição completa nem de uma tradição ortográfica, por exemplo. Situações como essas parecem requerer um trabalho mais aprofundado sobre as dinâmicas interdisciplinares possíveis entre, por um lado, as teorias de cunho mais formalista, cujo potencial para o registro e descrição das línguas é bastante grande, e as teorias de base sociológica, filosófica ou psicológica que apontam para aspectos da linguagem que não aqueles relativos à estrutura da língua, mas que têm dado base a 
avanços nos estudos sobre o ensino e a aprendizagem. É possível que, a partir daí, se possa esboçar de forma mais específica um perfil para o licenciado em Letras, tendo em vista o fato de que pelo menos uma parte dos professores formados no país deverá atuar naqueles locais em que, por "dificuldades operacionais" ou quaisquer outras razões, as equipes de exames nacionais e internacionais nem sempre se aventuram a ir.

\section{Conclusões}

As duas experiências relatadas nesse artigo diferem bastante, tanto em relação ao contexto em que foram realizadas quanto em relação às bases epistemológicas nas quais se ancoraram. Apesar disso, como propusemos no início, elas nos permitem, justamente por isso, pincelar alguns problemas gerais concernentes ao ensino de língua no Brasil. $\mathrm{O}$ primeiro e mais evidente desses problemas é, sem dúvida, o trabalho que ainda resta a ser feito para se reconhecer a natureza exata dos problemas que se enfrentam nas escolas.

No primeiro caso, aparentemente mais próximo do contexto da maioria dos leitores, falamos da detecção de uma situação que, embora relativamente simples, em geral passa despercebida nas escolas e acaba gerando, em longo prazo, consequências muito negativas no percurso escolar de alguns alunos. Ao enfatizar a questão dos métodos ou das filiações teóricas ${ }^{17}$, historicamente, a alfabetização tem fechado os olhos para os dados que poderiam lhe saltar à vista e, com isso, perpetua entraves diversos no acesso à escrita e à leitura.

De outro lado, a segunda experiência exemplifica um pouco de um universo desconhecido de contextos em que a escola brasileira ainda precisa se (re)inventar. Esses contextos, pouco ou nada contemplados pelos sistemas de avaliação nacionais, e conhecidos em geral por meio de pesquisas pontuais, permanecem como um desafio

${ }^{17}$ Impossível não fazer remissão ao relatório apresentado pelo "Painel Internacional de Especialistas em Educação Infantil", encomendado pela Comissão de Cultura e Educação da Câmara dos Deputados para apresentação durante um seminário em 2003, e à discussão que girou em torno desse documento. Sobre isso, vale a pena a leitura do trabalho de Belintane (2006b). 
que apenas recentemente começa a ser reconhecido como tal. Entre as questões que deverão entrar em pauta nesse campo, há que se considerar a necessidade de se assumir a possibilidade de existência de uma escola bilíngue no Brasil, uma vez que são relativamente numerosos os casos de bilinguismo ou plurilinguismo em comunidades indígenas. Há que se considerar, também, as peculiaridades da educação indígena, tradicionalmente abordada a partir de referenciais da educação de adultos, por um lado, e de campos tradicionalmente dedicados ao estudo das questões indígenas, como a Antropologia e a Linguística, por outros. Uma questão que se poderia levantar a esse respeito é se, de fato, se trata da mesma coisa falar em preservação de línguas indígenas, descrição de línguas indígenas e alfabetização em línguas indígenas.

Apesar da grande disparidade entre os contextos que informam as duas experiências aqui discutidas, acreditamos que há outros problemas gerais que podem ser apontados, ainda a guisa de conjecturas. Algumas questões que podemos formular:

- Que papel a oralidade pode exercer nas iniciativas de preservação de línguas indígenas e na própria gestação de suas escritas, levando em conta o papel que ela exerceu na gestação da escrita de tradição ocidental? Dado o fato de que as pesquisas com crianças têm mostrado que o domínio de uma cultura oral "desútil”, voltada para um trabalho simbólico sobre o sujeito e não para finalidades práticas, em geral facilita seu acesso à lógica da escrita, que elementos das culturais orais tradicionais indígenas poderiam dar estofo para o processo de introdução da escrita em sua língua? Que textos, nessas culturas, fariam as vezes dos gêneros orais lúdicos e mitopoéticos que há gerações vêm escorando o sujeito ocidental a ingressar no mundo da escrita?

- A preservação de uma língua indígena depende e é garantida apenas pela alfabetização de gerações mais novas nessa língua? Isto é o mesmo que indagar: em que medida, ao passar a escrever em uma língua indígena, uma comunidade tem garantido o direito e a possibilidade de preservar outros traços culturais que lhe são próprios e que encontraram expressão, algum dia, em sua língua de tradição oral?

- A ortografia de uma língua indígena deve necessariamente pautar-se pelo princípio de biunivocidade na relação grafema-fonema? Esta pergunta leva a outras conjecturas que, até onde sabemos, pouco 
têm sido feitas. Levando-se em consideração as características das escritas infantis, refletidas sempre na filogênese dos sistemas de escrita, podese perguntar, por exemplo: seria possível, e desejável, que uma língua indígena adotasse um sistema de escrita não alfabético (silábico, logográfico)? Caberia abrir essa possibilidade às comunidades?

Estas questões, por ora, permanecem sem respostas definidas, à espera de novos dados e experiências que aclarem as consequências que elas podem ter. Ficam, no entanto, como encaminhamentos possíveis diante de desafios que nos convocam a superar tradições e nos aventurarmos na incerteza de fundar novos caminhos.

\section{Referências}

ALLOUCH, J. Letra a letra. Transcrever, traduzir, transliterar. Trad. Dulce Duque Estrada. Rio de Janeiro: Campo Matêmico, 1995.

ARAÚJO, L.M.S. Semântica gerativa da língua gavião-jê. 1977. Dissertação (Mestrado em Linguística) - Universidade Federal de Santa Catarina, Florianópolis. 1977.

- Aspectos da língua gavião-jê. 1989. Tese (Doutorado em Linguística) - Universidade Federal do Rio de Janeiro, Rio de Janeiro. 1989.

BELINTANE, C. Abordagem da oralidade e da escrita na escola a partir da tessitura interdisciplinar entre a psicanálise e a lingüística. In: PSICANÁliSE, EDUCAÇÃO E TRANSMISSÃO, 6., São Paulo, 2006a. Proceedings online... Disponível em: <http:// w w w. p r o c e e d i n g s. s c i e l o . b r / scielo.php?script $=$ sci_arttext\&pid=MSC0000000032006000100002\&lng $=$ en\&nrm=abn>. Acesso em: 30 abr. 2011.

- Leitura e alfabetização no Brasil: uma busca para além da polarização. Educação e Pesquisa, São Paulo, v. 32, n. 2, p. 261-277, maio/ ago. 2006b. 
Vozes da escrita: em tempos de crianças e menestréis. Estilos da Clínica, v. 13, n. 25, p. 36-51, 2008.

BRAGGIO, S.L.B. (Org.). Contribuições da lingüística para a alfabetização. Goiânia: Editora da UFG, 1995.

BRASIL. Ministério da Educação e do Desporto. Lei no 9.394, de 20 de dezembro de 1996. Estabelece as diretrizes e bases da educação nacional. Diário Oficial da União, Brasília, DF, 23 dez. 1996. p. 27833. Disponível em: <http://www.planalto.gov.br/ccivil_03/leis/ L9394.htm>.

BRASIL. Ministério da Educação e do Desporto. Secretaria de Educação Fundamental. Referencial Curricular Nacional para as Escolas Indígenas. Brasília: MEC/SEF, 2005.

CONSELHO NACIONAL DE EDUCAÇÃO. Câmara Superior de Educação. Parecer n. ${ }^{\circ}$ : CNE/CES 492/2001. Diretrizes Curriculares Nacionais dos cursos de Filosofia, História, Geografia, Serviço Social, Comunicação Social, Ciências Sociais, Letras, Biblioteconomia, Arquivologia e Museologia. Rel.: Eunice Ribeiro Durham, Silke Weber e Vilma de Mendonça Figueiredo. Diário Oficial da União, Brasília, DF, 9 jul. 2001. Seção 1e, p. 50. Disponível em: <http://portal.mec.gov.br/ cne/arquivos/pdf/CES0492.pdf>.

CAGLIARI, L. C. Alfabetização e lingüística. 10. ed. São Paulo: Scipione, 2008.

FERREIRA, M.N.O. Estudo morfossintático da língua Parkatêjê. 2003. Tese (Doutorado em Linguística) - Universidade Estadual de Campinas, Campinas. 2003.

- Morfossintaxe da lingua Parkatêjê. LINCOM Studies in Native American Linguistics. LINCOM Europa: München. 2005.

- Variação linguística e alternância de código em Parkatêjê. Revista da Pesquisa \& Pós-Graduação, Universidade Federal de Ouro Preto (UFOP), v. 1, p. 1-15, 2010. 
FERREIRA-SILVA, M. Contato entre línguas, perda linguística e identidade étnica: notas sobre o povo parkatêjê. Cadernos de Letras da UFF - Dossiê: Letras, linguística e suas interfaces, n. 40, p. 239-247, 2010 .

FERREIRO, E. Reflexões sobre alfabetização. 2. ed. Trad. Horácio Gonzalez. São Paulo: Cortez, 1985. (Coleção Polêmicas do Nosso Tempo, n. 17).

FREIRE, P. Educação como prática da liberdade. Rio de Janeiro: Paz e Terra, 1967.

. Pedagogia do oprimido. Rio de Janeiro: Paz e Terra, 1970.

- A importância do ato de ler: em três artigos que se completam. São Paulo: Cortez, 1986.

FREUD, S. O chiste e sua relação com o inconsciente. In: OBRAS completas de Sigmund Freud, Edição Standard brasileira. Rio de Janeiro: Imago, 1987.

HAVELOCK, E. A equação oralidade-cultura escrita: uma fórmula para a mente moderna. In: OLSON, D. R.; TORRANCY, N. Cultura escrita e oralidade. Trad. Valter Lellis Siqueira. São Paulo: Ática, 1995. p. $17-34$.

LACAN, J. A identificação. Seminário inédito, 1961-1962.

LEMLE, M. Guia teórico do alfabetizador. 6. ed. São Paulo: Ática, 1991.

OLIVEIRA, J. de (Org.). Constituição da República Federativa do Brasil: promulgada em 5 de outubro de 1988. 4. ed. São Paulo: Saraiva, 1990. 168 p. (Série Legislação Brasileira).

PISA 2000. Relatório Nacional. Brasília: [s.n.], dez. 2001. Disponível em: <http://download.inep.gov.br/download/internacional/pisa/ PISA2000.pdf $>$.

POMMIER, G. Naissance et renaissance de l'écriture. Paris: Presses Universitaires de France, 1993. 